\title{
Improcedencia de las sanciones por extemporaneidad y por no declarar cuando se presenta oportunamente la declaración de retención en la fuente sin pago total*
}

\section{The Sanctions for Not Declaring and for Declaring Extemporaneously are not Applicable when the Withholding Tax Statement is presented on time but Without Total Payment}

\author{
DAVId Rueda MANTilla ${ }^{1}$
}

\section{Sumario}

Introducción. I. Distinción entre obligaciones sustanciales y deberes formales. II. Implicaciones de que una declaración no produzca efecto legal alguno o que se entienda por no presentada. III. Sanciones por extemporaneidad y por no declarar. A. Principios para interpretar las normas sancionatorias del Estatuto Tributario. B. Conducta descrita en las normas que contienen las sanciones por extemporaneidad y por no declarar. IV. Improcedencia de las sanciones por extemporaneidad y por no declarar cuando se presenta oportunamente la declaración de retención en la fuente sin pago total en tiempo. V. Conclusiones. Bibliografía.

\section{Resumen}

El artículo 15 de la Ley 1430 de 2010 estableció que "las declaraciones de retención en la fuente presentadas sin pago total no producirán efecto legal alguno, sin necesidad de acto administrativo que así lo declare". Con esta norma, se ha entendido que, para

* DOI: https://doi.org/10.18601/16926722.n11.03

${ }^{1}$ Abogado (2011), Especialista en Gestión Pública e Instituciones Administrativas (2012) y Magíster en Derecho Público para la Función Administrativa (2013) de la Universidad de los Andes; Master of Science with Merit in Law and Finance: Law and Corporate Finance (2015) de Queen Mary University of London; Especialista en Derecho Tributario, de la Universidad Externado de Colombia (2017); actualmente se encuentra cursando la Especialización en Derecho de Sociedades, en la Universidad Javeriana; tiene experiencia en el sector público (Fiscalía General de la Nación) y en este momento se desempeña como abogado en temas relacionados con Derecho corporativo, Derecho tributario y Derecho penal tributario.Correo-e: david@ruedamantilla.com 
todos los efectos legales, presentar una declaración de retención en la fuente sin pago es equiparable a no presentarla. Por esta razón, existe la creencia generalizada de que proceden las sanciones por extemporaneidad y por no declarar cuando un agente retenedor presenta dicha declaración sin pago total.En el presente artículo se argumenta que cuando esto ocurre, el agente retenedor no ha incurrido en ninguna conducta que amerite la imposición de dichas sanciones, de conformidad con una interpretación armónica del ordenamiento tributario.

Palabras clave: Declaraciones ineficaces, Declaración de retención en la fuente sin pago, Sanción por extemporaneidad, Sanción por no declarar, Sanciones relacionadas con las declaraciones tributarias.

\section{Abstract \\ Article 15 of the Law 1430 of 2010 es- tablished that "withholding tax declarations submitted without the whole payment will not produce any legal effect, without any act being required". Because of this regula- tion it has been understood that, for all legal purposes, the submission of a withholding tax declaration without the whole payment is equivalent to avoiding the submission at all. For this reason, it is generally believed that if a withholding tax declaration is sub- mitted with no payment, penalties related with tax declarations must be imposed. This paper argues that these penalties should not be imposed under these circumstances ac- cording to a harmonized interpretation of the legal system.}

Keywords: Ineffective Declarations, Withholding Tax Declarations Submitted with no Payment, Penalty for Declaring out of time, Penalty for Avoiding to Declare, Penalties Related with Tax Declarations.

\section{Introducción}

La Ley 1430 de 2010, en su artículo 15, adicionó el Estatuto Tributario con el artículo 580-1. Esta norma establece que "las declaraciones de retención en la fuente presentadas sin pago total no producirán efecto legal alguno, sin necesidad de acto administrativo que así lo declare". En virtud de esta norma, se ha entendido que cuando un agente retenedor presenta su declaración de retención en la fuente sin pago, se entiende que no la ha presentado y, por tal motivo, proceden las sanciones por extemporaneidad y por no declarar. Se podría decir que el entendimiento de esta norma es que cuando se cumple con el deber formal (presentar la declaración en tiempo) sin cumplir con la obligación sustancial (realizar el pago en tiempo) se entiende que el agente retenedor no solo ha incumplido con la obligación sustancial, sino que también ha incumplido con el deber formal.

El presente artículo de reflexión pretende hacer una crítica a esta situación en cuanto a que se ignora la distinción entre la obligación sustancial y los deberes formales, al quitarle validez al cumplimiento de los deberes formales cuando se incumple con las obligaciones sustanciales. Así mismo, el propósito de este texto es el de demostrar que, así las declaraciones de retención en la fuente presentadas sin pago no produzcan efecto legal alguno de conformidad con el artículo 580-1 del Estatuto Tributario, cuando un agente retenedor presenta una declaración de retención en la fuente sin pa- 
go, no es procedente imponer las sanciones por no declarar ni la sanción por declarar extemporáneamente.

Para cumplir con los objetivos planteados en el párrafo anterior, este documento tiene la siguiente estructura: en primer lugar, se hace una diferenciación entre la naturaleza jurídica de las obligaciones tributarias de carácter sustancial y los deberes formales; segundo, se analiza el alcance del artículo 580-1 del Estatuto Tributario, en cuanto a cuáles son las declaraciones que no producen efecto legal alguno y cuáles son las consecuencias jurídicas de que una declaración presentada no produzca ningún efecto legal; en tercer lugar, se hace referencia a las sanciones relacionadas con las declaraciones tributarias y las causales para imponerlas; cuarto, se presentan las razones por las cuales son improcedentes las sanciones por el incumplimiento del deber de declarar a tiempo cuando se presenta oportunamente una declaración de retención en la fuente sin pago total; finalmente, a modo de resumen del trabajo, se presentan unas breves conclusiones.

\section{Distinción entre obligaciones formales y deberes sustanciales}

La obligación era definida por las Institutas de Justiniano como "un vínculo de derecho que nos constriñe a cumplir con una prestación a favor de otro" (Tamayo Lombana, 2008, p. 28). Esta definición, que aún sigue siendo aceptable en nuestra época, trae consigo los siguientes tres elementos: un vínculo de Derecho, una prestación, la presencia de un deudor y un acreedor. Consecuentemente con este concepto, la obligación tributaria se puede definir como “el vínculo jurídico que le permite al Estado exigir de los contribuyentes el cumplimiento de prestaciones pecuniarias sin que exista estipulación contractual previa ni promesa de contraprestación futura directa o determinada” (Sierra Mejía, 1999, p. 393).

De acuerdo con lo anterior, la obligación tributaria es similar a la civil, pero no idéntica, en tanto que "hay un acreedor que es el Estado, un deudor que es el sujeto pasivo del tributo y una prestación consistente en dar una suma de dinero, implicando adicionalmente la existencia de un derecho subjetivo" (Marín Elizalde, 2015, p. 317). Como se puede ver, la prestación derivada de la obligación tributaria consiste exclusivamente en dar una suma de dinero al Estado. Por esta razón, esta obligación ha sido conocida por la doctrina como una obligación de carácter sustancial.

Vale la pena mencionar que, tal y como ha sido desarrollada por la doctrina, la obligación tributaria se desprende de una relación jurídico-tributaria existente entre el Estado y el contribuyente. Como bien lo señala el profesor Mauricio Marín, en virtud de la relación jurídico-tributaria existen numerosas figuras legales que "exigen un comportamiento especial de los particulares, pues el objeto de la misma va más allá del pago del tributo como consecuencia de la realización del hecho generador" (2015, p. 314). Dicho comportamiento exigido a los particulares, además del pago del tributo, implica la realización de una serie de conductas encaminadas a "determinar la existencia y cuantificación de la obligación sustancial, esto para facilitar la investigación tributaria o la recaudación de las exacciones" (2015, p. 319). 
Entonces, de la relación jurídico tributaria nace el deber de pagar el tributo (obligación tributaria sustancial), así como el deber de realizar una serie de actuaciones encaminadas a determinar el monto de mismo (deberes formales). Con respecto a estos últimos, hay que tener presente que existe un debate doctrinal sobre si son o no obligaciones tributarias. Por una parte, atendiendo a que de conformidad con el artículo 1495 del Código Civil las obligaciones pueden ser de dar, hacer o no hacer, se ha entendido que los deberes formales son obligaciones accesorias de hacer. Esta tesis se refuerza con el hecho de que el título segundo del libro quinto del Estatuto Tributario se denomine: "Deberes y obligaciones formales". Por otra parte, esta posición ha sido criticada en cuanto a que "en materia tributaria los deberes formales tributarios no son accesorios, puesto que pueden ser independientes de las obligaciones sustanciales y además cada uno tiene su propio régimen de responsabilidad por su incumplimiento (Marín, 2015, p. 319).

Siendo que no es el objetivo del presente texto entrar en dicho debate, nos limitaremos a concluir que en materia tributaria existen obligaciones sustanciales y deberes formales. Las primeras, consistentes en pagar un tributo y los segundos, en realizar algunas actuaciones tendientes a determinar el monto de dicho tributo y evitar la evasión. Dentro de estas conductas encontramos, entre otras, las siguientes:

1. Deber de presentar declaraciones tributarias.

2. Deber de informar dirección y actividad económica en las declaraciones tributarias
3. Obligación de inscribirse en el RUT.

4. Obligación de informar el cese de actividades.

5. Obligación de expedir facturas o documento equivalente.

6. Obligación de exigir factura o documento equivalente.

7. Deber de llevar contabilidad.

8. Deber de suministrar información y atender los requerimientos de la Administración de impuestos.

Teniendo en cuenta que los objetivos de los deberes formales se encuentran encaminados a la determinación del tributo que se debe pagar y a evitar la evasión, consideramos que es deseable que la legislación tributaria distinga entre las obligaciones tributarias sustanciales y los deberes formales en cabeza del contribuyente. Esto es que el deber formal se entienda cumplido independientemente de si se cumple con la obligación sustancial y viceversa. Esto en el entendido que si el contribuyente en un momento determinado no tiene la capacidad económica para extinguir la obligación sustancial, tenga el incentivo de realizar sus deberes formales y, de esta manera, cumplirle al Estado y a la Administración tributaria así sea de forma parcial.

Debido a lo anterior, creemos que es inconveniente cuando la legislación entiende que, en algunos casos, se da por incumplido el deber formal si no se ha extinguido la obligación sustancial. Esto en cuanto a que, si el contribuyente no se encuentra con la capaci- 
dad de extinguir la obligación tributaria, no va a tener ningún incentivo en colaborarle a la Administración de impuestos mediante el cumplimiento de los deberes formales.

Frente a esta a opinión, algunos podrían considerar que como la retención en la fuente no es un impuesto propio sino tributos recaudados a terceros, no le cabe el juicio de capacidad económica o contributiva. Si bien esto es cierto, independientemente del análisis de capacidad contributiva, resulta claro que en la práctica los retenedores pueden no tener la caja para pagar el tributo, pero sí la intención de cumplir con sus deberes formales o, al menos, de presentar la declaración tributaria. Así pues, incluso en este caso, si la legislación no da por cumplido el deber de declarar a quien lo haga sin pago, el agente retenedor no tendrá ningún incentivo para presentar su declaración.

\section{Implicaciones de que una declaración no produzca efecto legal alguno o que se entienda por no presentada}

Es posible hacer una distinción entre las declaraciones que no producen efecto legal alguno y las que se entienden por no presentadas. Con respecto a las primeras, el artículo 580-1 del Estatuto Tributario establece que "las declaraciones de retención en la fuente presentadas sin pago total no producirán efecto legal alguno, sin necesidad de acto administrativo que así lo declare". En relación a las segundas, el artículo 580 del Estatuto Tributario establece lo siguiente:

Declaraciones que se tienen por no presentadas. -No se entenderá cumplido el deber de presentar la declaración tributaria, en los siguientes casos:

a) Cuando la declaración no se presente en los lugares señalados para tal efecto;

b) Cuando no se suministre la identificación del declarante, o se haga en forma equivocada;

c) Cuando no contenga los factores necesarios para identificar las bases gravables;

d) Cuando no se presente firmada por quien deba cumplir el deber formal de declarar; o cuando se omita la firma del contador público o revisor fiscal existiendo la obligación legal.

Como se puede ver de las normas citadas, es claro que cuando una declaración se tiene por no presentada de conformidad con el artículo 580 del Estatuto Tributario, la consecuencia jurídica es que no se entiende cumplido el deber de declarar. Por lo tanto, para estos casos, es claro que si la legislación entiende que no se cumplió con el deber de declarar son procedentes las sanciones por no declarar o por extemporaneidad en caso de que posteriormente, y de forma extemporánea, se presente otra declaración con los requisitos legales. Sin embargo, frente a las declaraciones que no producen efecto legal alguno, es necesario hacer un análisis más profundo para determinar cuáles son los efectos legales de las declaraciones tributarias y, por ende, los efectos que no producen las declaraciones de retención en la fuente presentadas sin pago. 
Para empezar este análisis, es necesario desarrollar el concepto de declaración tributaria. Desafortunadamente, esta no se encuentra definida por el ordenamiento colombiano. Por esta razón, es necesario acudir a la doctrina para acuñar una definición de este concepto.

Para Hinestrosa (Piza Rodríguez y Castro Arango, 2010, p. 602) la declaración tributaria puede ser definida como "un comportamiento humano al que la ley dota de consecuencias jurídicas precisas y definidas integralmente por ella, añadiendo su carácter espontáneo o no, elaborada en cumplimiento de un deber de colaboración con la Administración, con el propósito de comunicar formalmente datos de relevancia tributaria". La declaración tributaria también ha sido definida como "un documento privado, donde se reconoce o manifiesta la realización de cualquier hecho relevante para la aplicación de los tributos; documento que además goza de reserva por aplicación de los artículos 15 de la Constitución Política y 583 del Estatuto Tributario" (Cermeño, De Bedout, García y Clopatofsky, 2016, p. 38). Hablando específicamente de la declaración de retención en la fuente, como bien lo señala el profesor Julio Roberto Piza, esta "tiene la misma naturaleza de todas las declaraciones tributarias, esto es, un documento que tiene por objeto declarar los hechos generadores, determinar el monto de la obligación, por tanto, servir de título ejecutivo de la misma y, por último, servir de instrumento de pago" (Piza Rodríguez, 2010, 493).
De las anteriores definiciones podemos ver que el principal efecto legal de una declaración tributaria no es otro que el reconocimiento de un hecho relevante para la aplicación de un tributo. Dicho reconocimiento, como bien lo señalan Piza y Castro, cumple con dos funciones: en primer lugar, con respecto a las declaraciones que incorporan la autoliquidación de un impuesto, "dar inicio al procedimiento de gestión"; en segundo lugar, la determinación "de la actividad administrativa de fiscalización y liquidación” (2010, p. 607).

Además de lo anterior, si en la declaración tributaria el contribuyente reconoce la existencia de un tributo que debe pagar al Estado, la consecuencia sería que en ella se incorporaría una obligación clara, expresa y exigible. El efecto jurídico de esta circunstancia es que las declaraciones tributarias, al ser el reconocimiento por parte del contribuyente de una suma que debe pagar al Estado, prestan mérito ejecutivo ${ }^{2}$. Por esta razón, el numeral primero del artículo 828 del Estatuto Tributario establece que "las liquidaciones privadas y sus correcciones, contenidas en las declaraciones tributarias presentadas, desde el vencimiento de la fecha para su cancelación" prestan mérito ejecutivo.

De lo dicho en los dos párrafos precedentes, tenemos que los efectos jurídicos de una declaración tributaria son los siguientes cuatro:

\footnotetext{
${ }^{2}$ Ya hemos advertido que las declaraciones electrónicas no cumplen con los requisitos para constituir un título ejecutivo y, por tanto, no deberían prestar mérito ejecutivo. Al respecto, consultar: Rueda Mantilla, David (2016).
} 
1. Que se pone en conocimiento de la Administración de impuestos, de manera formal, la ocurrencia de un hecho relevante para la aplicación de los tributos.

2. Que se da inicio al procedimiento de gestión tributaria.

3. Que los datos puestos de presente en la declaración tributaria sirven para determinar la actividad administrativa y de fiscalización.

4. Que la declaración tributaria constituye título ejecutivo.

En este sentido, es posible concluir que cuando el artículo 580-1 del Estatuto Tributario establece que las declaraciones de retención en la fuente que sean presentadas sin pago no producirán efecto legal alguno, lo que está diciendo es que no tienen la capacidad jurídica de generar ninguno de los anteriores cuatro efectos. En la práctica, y atendiendo a la forma como está redactada la norma, una declaración de retención en la fuente presentada sin pago, a pesar de no generar ninguno de los efectos mencionados, se entiende plenamente presentada.

Es cierto que algunos podrían entender -como lo hacen Cermeño, De Bedout, García y Clopatofsky- que si se entiende que una declaración no produce efectos jurídicos es como si la misma nunca se hubiera presentado (2016, p.48). Este ha sido un entendimiento generalizado y ha sido el adoptado por la Administración de impuestos. Sin embargo, tenemos motivos para creer que una cosa es que una declaración no produzca efectos legales y otra muy distinta es que la misma se entienda como no presentada.
Tal y como se manifestó al principio del presente acápite, el legislador, en el Estatuto Tributario, hizo una distinción clara entre las declaraciones que se entienden como no presentadas (artículo 580) y las que no producen efectos legales (artículo 580-1). Entonces, es claro que si el legislador hubiera querido que las declaraciones de retención en la fuente presentadas sin pago se entendieran como no presentadas, lo hubiera dicho literalmente, como lo hizo en el artículo 580 del Estatuto Tributario. Lo que quiso el legislador, según lo dijo expresamente en el artículo 580-1 del Estatuto Tributario, fue manifestar que dichas declaraciones eran ineficaces.

Vale la pena mencionar que con anterioridad a la entrada en vigencia de la Ley 1430 de 2010, las declaraciones de retención en la fuente presentadas sin pago eran de las que se entendían como no presentadas. Esto en cuanto a que el literal E del artículo 580, el cual fue derogado por el artículo 67 de la Ley 1430 de 2010, así lo contemplaba. Así pues, el legislador, mediante la Ley 1430 no solo manifestó que las declaraciones de retención en la fuente presentadas sin pago no producirían efecto legal alguno, sino además dejó claro que las mismas no eran de las que se entendían como no presentadas. Por lo tanto, estas declaraciones sí se entienden como presentadas pero no producen efecto legal alguno.

\section{Sanciones por extemporaneidad $y$ por no declarar}

Teniendo en cuenta que el objetivo del presente artículo es el de demostrar que son improcedentes las sanciones por extemporaneidad y por no declarar cuando se presenta una declaración de retención en la fuente de 
manera oportuna, pero sin pago total, el presente acápite tiene el objetivo de analizar las normas que contienen estas sanciones, para determinar las circunstancias en las que son procedentes. Para ello, en primer lugar, se mencionarán los principios bajo los cuales se deben interpretar las normas sancionatorias del Estatuto Tributario y, segundo, se analizará la conducta descrita en las normas que contienen las sanciones por extemporaneidad y por no declarar.

\section{A. Principios para interpretar las normas sancionatorias del Estatuto Tributario}

Actualmente, los principios que deben regir las sanciones tributarias son exclusivamente los que ha señalado la jurisprudencia. Esto en cuanto a que si bien es cierto que la Ley 1607 de 2012 consagró expresamente algunos principios que eran aplicables al régimen sancionatorio, desafortunadamente la última reforma tributaria contenida en la Ley 1819 de 2016 derogó dichas disposiciones ${ }^{3}$. Por esta razón, procedemos a mirar cuáles son los principios que deben regir el Derecho sancionatorio administrativo a la luz de la jurisprudencia de nuestras altas cortes, particularmente la Corte Constitucional.

La Constitución Política de 1991 "produjo un cambio sustancial en materia sancionatoria tributaria, pues las actuaciones administrativas quedaron expresamente regidas por las garantías del debido proceso" (Noreña Ospina, 2016, p. 153). A pesar de esta situación, la jurisprudencia del Consejo de
Estado ha continuado con su rígida postura administrativista según la cual, al ser las normas del Derecho sancionatorio claras, no se requiere ni es procedente la aplicación de los principios del Derecho penal en el Derecho sancionatorio tributario (Cahn-Speyer Wells, 2016, p. 328). Afortunadamente, la jurisprudencia de la Corte Constitucional ha ido por una vía diferente, al considerar que las normas sancionatorias no son completas ni claras y que para colmar sus lagunas se deben aplicar los principios del Derecho penal con algunos matices (Noreña Ospina, 2016, p. 158).

Si bien es cierto que la postura de la Corte Constitucional es más conveniente que la del Consejo de Estado, sigue teniendo algunas complicaciones. Como bien lo señala el profesor Paul Cahn-Speyer, resulta desafortunado que la Corte Constitucional haya manifestado "la necesidad de aplicar las garantías del Derecho Penal al Derecho Administrativo, pero con 'algunas atenuaciones' o "con ciertos matices"' (2016,p. 316). Esto en cuanto que con esta postura la Corte acoge "una concepción intelectualmente indefinida que, desde entonces, ha hecho que la función estabilizadora del Derecho sea inoperante" (Cahn-Speyer Wells, 2016, p. 302). A pesar de la anterior situación, es claro que de conformidad con el artículo 29 de la Constitución Política y la jurisprudencia de la Corte Constitucional, las garantías mínimas del proceso penal son aplicables al Derecho sancionatorio tributario así sea con algunas atenuaciones.

${ }^{3}$ Consideramos que vale la pena estudiar en un próximo artículo las razones que llevaron al legislador a derogar el artículo 197 de la Ley 1607 de 2012, el cual contenía los principios que debían regir el sistema sancionatorio, y la conveniencia de haberlo hecho. 
Así pues, a la luz de la jurisprudencia de la Corte Constitucional, los principios del Derecho penal son aplicables al Derecho sancionatorio tributario. Dentro de estos principios, de acuerdo con el capítulo único del título primero del libro primero del Código Penal, encontramos los siguientes: 1. Dignidad humana; 2. Integración; 3. Necesidad, proporcionalidad y razonabilidad; 4. Función de la pena (o de la sanción); 5. Legalidad; 6. Igualdad; 7. Prohibición de doble incriminación; 8. Punibilidad, tipicidad, antijuridicidad y culpabilidad.

Así mismo, para efectos de los propósitos del presente trabajo, es necesario prestarle particular atención al principio del acto, del hecho, o de la objetividad material del hecho punible. Según lo manifiesta el profesor Fernando Velásquez, de conformidad con este principio, "para que pueda afirmarse la configuración de un delito (hecho punible), tiene que verificarse la existencia de una conducta humana activa u omisiva" (Velásquez, 1988, p. 23). Esta conducta se debe ajustar exactamente a la descrita en el tipo penal o, para el caso del Derecho sancionatorio, en la norma que contempla la sanción.

\section{B. Conducta descrita en las normas que contienen las sanciones por extemporaneidad y por no declarar}

El Estatuto Tributario, en los artículos que van del 641 al 650-2, contempla una serie de infracciones tributarias que solo pueden ser llevadas a cabo por "sujetos que se encuentran sometidos al deber formal de presentar declaración tributaria de algunos de los impuestos" (Zornoza Pérez y Muñoz Martínez, 2010, p. 852). Esto quiere decir que para poder incurrir en alguna de estas infracciones es necesario tener la condición de sujeto activo calificado al ser declarante. Para efectos de los objetivos del presente artículo, este acápite analizará las normas que contienen las sanciones por no declarar y por declarar extemporáneamente.

Con respecto a las sanciones por no declarar, el inciso primero del artículo $643 \mathrm{del}$ Estatuto Tributario establece lo siguiente:

Los contribuyentes, agentes retenedores o responsables obligados a declarar, que omitan la presentación de las declaraciones tributarias, serán objeto de una sanción equivalente a (...). (destacado fuera de texto).

Como se puede ver de la redacción de la norma, lo que se reprocha es una conducta de carácter omisivo. Según lo señala el profesor Fernando Velázquez, la tipicidad en estas conductas "surge de la diferencia entre el actuar realizado y el vertido en el dispositivo legal" (2007, p. 321). Para este caso en concreto, el actuar vertido en el dispositivo legal, según lo señalan los artículos 715 y 716 del Estatuto Tributario, es el de presentar la declaración tributaria dentro del mes siguiente a "la notificación del emplazamiento para declarar por parte de las autoridades tributarias" (Zornoza Pérez y Muñoz Martínez, 2010 p. 853).

De conformidad con lo anterior, para que se configure la conducta reprochada por la sanción por no declarar es necesario que se den los siguientes supuestos:

1. Que haya un sujeto que tenga la condición de declarante. 
2. Que dicho sujeto haya incumplido con la obligación de presentar las declaraciones tributarias y, como consecuencia de ello, haya sido emplazado para declarar por la Administración.

3. Que dentro del mes siguiente a que a dicho sujeto se le haya notificado el emplazamiento para declarar, el declarante persista renuente a cumplir con dicho deber.

Ahora bien, las sanciones por declarar extemporáneamente se encuentran consagradas en los artículos 641 y 642 del Estatuto Tributario. Estas normas, en relación con la conducta reprochada, establecen lo siguiente:

Inciso primero del artículo 641 del Estatuto Tributario:

Las personas o entidades obligadas a declarar, que presenten las declaraciones tributarias en forma extemporánea, deberán liquidar y pagar una sanción por cada mes o fracción de mes calendario de retardo, equivalente al cinco por ciento (5\%) del total del impuesto a cargo o retención objeto de la declaración tributaria, sin exceder del ciento por ciento (100\%) del impuesto o retención, según el caso (destacado fuera de texto).

Inciso primero del artículo 642 del Estatuto Tributario:

El contribuyente, responsable, agente retenedor o declarante, que presente la declaración con posterioridad al emplazamiento. deberá liquidar y pagar una sanción por extemporaneidad por cada mes o fracción de mes calendario de retardo, equivalente al diez por ciento (10\%) del total del impuesto a cargo o retención objeto de la declaración tributaria, sin exceder del doscientos por ciento (200\%) del impuesto o retención, según el caso (destacado fuera de texto).

Tal y como se puede ver de las normas transcritas, las conductas reprochadas por la sanción por extemporaneidad consisten en presentar las declaraciones tributarias de forma extemporánea o presentar la declaración tributaria con posterioridad al emplazamiento para declarar. Para que sea procedente la imposición de estas sanciones, es necesario "que haya un incumplimiento del deber de declarar en los plazos fijados por las normas generales, y que ese incumplimiento sea subsanado posteriormente" (Zornoza Pérez y Muñoz Martínez, 2010, p. 853). Si el incumplimiento se subsana a motu proprio sin que la administración haya proferido el emplazamiento para declarar, se aplica la sanción contenida en el artículo 641 del Estatuto. Si el incumplimiento se subsana dentro del mes siguiente a la notificación del emplazamiento para declarar, procede la sanción del artículo 642.

De acuerdo con lo dicho en las líneas anteriores, para que se configure la sanción por extemporaneidad es necesario que se den los siguientes supuestos:

1. Que haya un sujeto que tenga la condición de declarante.

2. Que dicho sujeto no haya cumplido con la obligación de presentar alguna declaración dentro de los plazos fijados por las normas generales. 
3. Que dicho incumplimiento haya sido subsanado a motu proprio, antes de la notificación del emplazamiento para declarar, o dentro del mes siguiente a dicha notificación.

Es importante resaltar que la sanción es menos grave si el contribuyente subsana su incumplimiento a motu proprio a que si lo hace con ocasión del emplazamiento proferido por la Administración. Así mismo, las normas contemplan que el monto de la sanción se graduará "en función de los meses de retraso con los que se presente la declaración" (Zornoza Pérez y Muñoz Martínez, 2010, p. 853). Esto tiene todo el sentido, en cuanto a que entre más pronto se subsane la situación de incumplimiento, menos lesivo será el mismo para los fines de la Administración tributaria.

Sin perjuicio de lo anterior, compartimos la crítica hecha por Zornoza y Muñoz, según la cual "sancionar como infracción el simple retraso en el cumplimiento, incluso cuando posteriormente se presenta la declaración de forma espontánea, sin mediar requerimiento previo de la administración, resulta claramente excesivo y completamente ajeno a la idea de proporcionalidad" (2010,p.853).Así lo comparte la Sentencia C-818 de 2005 en cuanto a que la función de la sanción es la de prevenir y reprobar las conductas contrarias al ordenamiento y si el contribuyente subsana su incumplimiento a motu proprio no sería necesario prevenir o reprobar su conducta.

Por otro lado, vale la pena mencionar que la sanciones por extemporaneidad -al igual que las sanciones por corrección y por inscribirse extemporáneamente en el registro de vendedores- deben ser autoliquidadas por el contribuyente. Esto, como bien lo señalan Zornoza y Muñoz, es a todas luces inconstitucional porque vulnera el principio de presunción de inocencia y el derecho a no declarar contra sí mismo, los cuales se encuentran consagrados en los artículos 29 y 33 de la Constitución Nacional, respectivamente (Zornoza y Muñoz, 2010 p. 825). Este esquema de autoliquidación de sanciones ya fue demandado ante la Corte Constitucional por ser contrario al artículo 29 y por darles a los particulares funciones jurisdiccionales. Desafortunadamente, el máximo tribunal constitucional, en Sentencia C-506 de 2002, no contrastó las normas demandadas con el artículo 29 de la Constitución, sino que "prefirió demostrar que la aplicación de sanciones tributarias no corresponde al ejercicio de funciones jurisdiccionales (Zornoza y Muñoz, 2010, p. 826).

\section{Improcedencia de las sanciones por extemporaneidad y por no declarar cuando se presenta una declaración de retención en la fuente sin pago total en tiempo}

Tal y como ya se ha manifestado en el presente escrito, se ha entendido que, de conformidad con el artículo 580-1 del Estatuto Tributario, presentar una declaración de retención en la fuente sin pago total es equivalente a no presentarla. Esta interpretación, teniendo en cuenta las modificaciones realizadas por el artículo 270 de la Ley 1819 de 2016, traería las siguientes consecuencias:

1. Si se presenta la declaración de retención en la fuente sin pago, pero el agente retenedor es titular de un saldo a favor igual o superior a dos veces el valor de la retención 
a cargo, la misma no será ineficaz y, por tanto, no habría lugar a imponer sanciones.

2. Si se presenta la declaración de retención en la fuente sin pago antes del vencimiento del plazo para declarar oportunamente, la misma será eficaz siempre y cuando se realice el pago dentro de los dos meses siguientes contados a partir de la fecha del vencimiento del plazo para declarar.

3. Si se presenta la declaración de retención en la fuente sin pago y no se realiza ningún pago posteriormente, procedería la sanción por no declarar contemplada en el artículo 643 del Estatuto Tributario.

\section{Si se presenta la declaración de reten-} ción en la fuente sin pago y se realiza el pago de la misma después de los dos meses siguientes contados a partir de la fecha del vencimiento del plazo para declarar junto con una nueva declaración, procedería la sanción por extemporaneidad contenida en el artículo 641 del Estatuto Tributario.

5. Si se presenta la declaración de retención en la fuente sin pago y se realiza el pago de la misma después del emplazamiento para declarar junto con una nueva declaración, procedería la sanción por extemporaneidad contenida en el artículo 642 del Estatuto Tributario.

No obstante, tal y como se mencionó en el segundo acápite del presente documento, la consecuencia de presentar una declaración de retención en la fuente sin pago no es que la misma se entienda por no presentada. Como bien lo señala el artículo 580-1 del Estatuto Tributario, la consecuencia de presentar dicha declaración sin pago es que la misma no produzca efectos legales. Esta distinción es muy importante porque una cosa es que se entienda que la declaración no se presentó, caso en el que procederían las sanciones por no declarar o por extemporaneidad, y otra cosa es que la misma no produzca efectos legales, caso en el que no procederían las sanciones en mención, porque la declaración se entendería plenamente presentada en tiempo, independientemente de si produce o no produce efectos legales.

De acuerdo con lo dicho en el párrafo anterior, una declaración de retención en la fuente presentada sin pago no produce efectos legales, pero para todos los efectos prácticos la misma fue presentada. Caso contrario ocurre para los supuestos del artículo $580 \mathrm{del}$ Estatuto Tributario, en los que el legislador sí dijo de manera clara y expresa que, para esos casos, no se entenderá cumplido el deber de presentar la declaración tributaria. Así pues, es claro que cuando se presenta una declaración bajo los supuestos del artículo 580 del Estatuto, para todos los efectos legales, es como si la misma no se hubiera presentado $\mathrm{y}$, por lo tanto, procederían las sanciones por no declarar o por extemporaneidad, dependiendo del caso.

Es cierto que algunos podrían argumentar que uno de los efectos legales de presentar una declaración es que la misma se entienda presentada y, por tal motivo, si la misma no tiene la facultad de producir efectos legales no se podría entender como presentada. Este argumento fue compartido por la Corte Constitucional cuando, en la Sentencia C-102 de 2015, en la que precisamente se discutía la constitucionalidad del artículo 580-1, se dijo que cuando la declaración de retención en la fuente "no se presenta con el 
pago, se entiende que el agente retenedor no ha cumplido con su obligación" de declarar. No obstante, creemos que este argumento, así haya sido compartido por el máximo tribunal constitucional, no es convincente y, por tanto, no debe ser aplicado por los jueces por las siguientes cinco razones.

En primer lugar, el efecto legal de una declaración tributaria no es que la misma se entienda presentada. La presentación de una declaración es una conducta material del contribuyente y los efectos legales de la misma se encuentran consagrados en el ordenamiento. Dichos efectos legales, como bien se manifestó en el segundo acápite de este documento, son: que la administración conozca hechos relevantes para la aplicación de los tributos, que se inicie el procedimiento de gestión tributaria, que la información puesta de presente en la declaración tributaria sirva para las actividades de fiscalización y que la declaración tributaria constituya un título ejecutivo ${ }^{4}$. Por esta razón, así la legislación entienda que una declaración tributaria presentada sin pago no produce efectos legales, no se puede desconocer que materialmente la declaración de retención en la fuente sí fue presentada.

En segundo lugar, si el legislador hubiera querido que la consecuencia jurídica de presentar una declaración de retención en la fuente sin pago fuera que la misma no se entendiera presentada, lo hubiera dicho expresamente, como lo hizo en los supuestos del artículo 580 del Estatuto. Por esta razón, y atendiendo a una interpretación literal de la norma contenida en el artículo 580-1 del Estatuto Tributario, no se puede asumir que una declaración de retención en la fuente presentada sin pago se deba entender como no presentada. Además, vale la pena reiterar en que con anterioridad a la expedición de la Ley 1430 de 2010, estas declaraciones se entendían como no presentadas y que en el artículo 67 de esta ley el legislador derogó expresamente dicha disposición.

En tercer lugar, si bien es cierto que la Corte Constitucional en la Sentencia C-102 de 2015 manifestó que cuando la declaración de retención en la fuente "no se presenta con el pago, se entiende que el agente retenedor no ha cumplido con su obligación" de declarar, no es menos cierto que dicha afirmación fue realizada en la parte motiva del fallo o en el obiter dicta. Como bien lo ha manifestado de forma reiterada la jurisprudencia del máximo tribunal constitucional colombiano, el obiter dicta de una sentencia "no está inescindiblemente ligado con la decisión" y "no tiene fuerza vinculante" ya que solo constituye un criterio auxiliar de interpretación (Sentencia T-292 de 2006). Para el caso de la Sentencia C-102 de 2015, la Corte no estaba decidiendo sobre las implicaciones de que una declaración de retención en la fuente se considerara ineficaz. La Corte solo estaba analizando si sancionar con ineficacia, sin necesidad de acto administrativo que la declarase, las declaraciones de retención

\footnotetext{
${ }^{4}$ También creemos que si la declaración de retención en la fuente presentada sin pago total no tiene la facultad de producir efectos legales, no debería poder ser usada como prueba dentro de un proceso penal por la comisión del delito de Omisión de Agente Retenedor. Para profundizar más sobre este punto, se recomienda consultar: Rueda Mantilla, David (2017).
} 
en la fuente, vulneraba el derecho al debido proceso consagrado en el artículo 29 de la Constitución Nacional.

En cuarto lugar, como bien lo manifiesta la Corte Constitucional en la referida Sentencia C-102 de 2015, el artículo 580-1 del Estatuto Tributario no se encuentra redactado "como una condición para que se entienda cumplida la obligación de declarar". Esto quiere decir que la norma no menciona nada sobre si se entiende cumplido el deber de declarar cuando se presenta una declaración de retención en la fuente sin pago. Por lo tanto, si el legislador no mencionó que se entendía incumplido el deber de declarar en estos casos, no le corresponde al intérprete hacerlo.

En quinto lugar, tal y como lo vimos en el tercer acápite del presente artículo, los verbos rectores de las sanciones por no declarar y por extemporaneidad son los siguientes: presentar la declaración de forma extemporánea (artículo 641 del ET), presentar la declaración con posterioridad al emplazamiento (artículo 642 del ET) y omitir presentar las declaraciones tributarias (artículo 643 del ET). Como se puede ver, ninguno de estos verbos rectores sanciona la conducta de presentar una declaración de retención en la fuente sin pago que no sea susceptible de generar efectos jurídicos. De esa forma, cuando se presenta una declaración de retención en la fuente sin pago total de manera oportuna, así la misma sea ineficaz, no se realiza la conducta consistente en omitir presentar las declaraciones tributarias: materialmente se realizó la conducta de presentar la declaración así la misma no produzca efectos jurídicos. De igual manera, si la declaración se presenta oportunamente, así la misma sea ineficaz, no se realizó la conducta de presentar la declaración de forma extemporánea.

Consecuentemente con lo anterior, es necesario tener presente que al Derecho sancionatorio se le deben aplicar los principios del Derecho penal, incluyendo el principio de la objetividad material del hecho punible. De acuerdo con este principio, para que proceda una sanción la conducta se tiene que adecuar exactamente a la descrita en la norma que la contiene. Para este caso, la conducta es omitir presentar las declaraciones o hacerlo de forma extemporánea, pero no se dice nada con respecto al pago o frente a que dichas declaraciones deban ser de las que producen efectos legales.

De acuerdo con lo dicho en los últimos cinco puntos, la consecuencia jurídica de presentar una declaración de retención en la fuente sin pago es que la misma no produzca efectos legales, pero no que se entienda como no presentada. Así pues, en la práctica, la declaración se habría presentado y, por lo tanto, no se habría realizado ninguno de los verbos rectores contenidos en las sanciones por no declarar y por extemporaneidad. Por lo tanto, con la presentación de una declaración, así la misma sea ineficaz, se cumple el deber de declarar, de manera tal que sería improcedente interponer las sanciones por no declarar y por extemporaneidad.

Ahora bien, es cierto que algunos podrían argumentar que el legislador siempre ha entendido que sí proceden las sanciones por extemporaneidad y por no declarar cuando se presenta una declaración ineficaz, debido a que el artículo 272 de la Ley 1819 de 2016 
establece que "los agentes de retención que dentro de los cuatro (4) meses siguientes a la fecha de entrada en vigencia de esta Ley, presenten las declaraciones de retención en la fuente sobre las que al 30 de noviembre de 2016 se haya configurado la ineficacia consagrada en el artículo 580-1 del Estatuto Tributario, no estarán obligados a liquidar y pagar la sanción por extemporaneidad y los intereses de mora. No obstante, con respecto a este argumento vale la pena manifestar las siguientes dos cosas.

En primer lugar, se debe entender que el legislador está haciendo una amnistía que pretende condonar los intereses de las retenciones en la fuente no pagadas a tiempo y, para ello, también reiteró que no proceden las sanciones por extemporaneidad y por no declarar, tal y como se ha sostenido en el presente documento.

En segundo lugar, y teniendo en cuenta que al Derecho sancionatorio le aplican los principios del Derecho penal, el artículo décimo del Código Penal consagra el principio de tipicidad, según el cual la ley debe definir de manera inequívoca, expresa y clara las características básicas estructurales del tipo penal y, para el caso del Derecho sancionatorio, de la sanción. Así pues, aunque algunos puedan entender de la redacción del artículo 272 de la Ley 1819 de 2016 que el legislador entiende que proceden las sanciones por extemporaneidad y por no declarar cuando se presenta la declaración de retención en la fuente sin pago, para estos casos es claro que no se ha incurrido en la conducta reprochada por las normas sancionatorias, en la medida en que las declaraciones sí fueron presentadas, y que la sanción no procedería en virtud del prin- cipio de tipicidad. De esta forma, si este es el entendimiento del artículo 272 de la Ley 1819 de 2016, esta norma estaría asumiendo que hay una sanción que no se encuentra consagrada de forma inequívoca, expresa y clara y, por lo tanto, se podría predicar su inconstitucionalidad.

\section{Conclusiones}

Debido a que el artículo 580-1 del Estatuto Tributario establece que las declaraciones de retención en la fuente presentadas sin pago no producirán efecto legal alguno, se ha entendido que presentar dichas declaraciones sin pago es equivalente a no presentarlas y, por lo tanto, que proceden las sanciones por extemporaneidad y por no declarar. Esta postura, además de ser generalmente aceptada, es la compartida por la Administración de impuestos. En el presente texto se presentaron razones suficientes para creer que esta posición es inconveniente e incorrecta.

Por un lado, con respecto a la inconveniencia de esta posición, es necesario tener presente que de la relación jurídico tributaria entre el contribuyente y la Administración nacen obligaciones sustanciales (pagar el tributo) y deberes formales consistentes en realizar algunas actuaciones -como presentar las declaraciones- tendientes a determinar el monto de dicho tributo y evitar la evasión. Esto resulta conveniente en la medida en que los contribuyentes, independientemente de si pagan o no sus obligaciones sustanciales, deben cumplir el deber de colaborarle al Estado para que haya un idóneo manejo de la administración de los tributos. Por esta razón, es indeseable que el legislador contemple casos en los que el cumplimiento del deber formal se 
encuentre supeditado al cumplimiento de la obligación sustancial, ya que si el contribuyente no tiene la capacidad económica para pagar el tributo no tendrá ningún incentivo para realizar los deberes formales encaminados a colaborarle a la Administración de impuestos con su gestión de recaudo y fiscalización.

Frente a esta posición, algunos podrían considerar que como la retención en la fuente no es un impuesto propio sino tributos recaudados a terceros, no le cabe el juicio de capacidad económica o contributiva. Si bien esto es cierto, independientemente del análisis de capacidad contributiva, resulta claro que en la práctica los retenedores pueden no tener la caja para pagar el tributo, pero sí la intención de cumplir con sus deberes formales.

Por otro lado, el entendimiento que se tiene actualmente del artículo 580-1 del Estatuto Tributario es incorrecto porque, tal y como está redactada la norma, la presentación de una declaración de retención en la fuente sin pago total, no implica que la misma se entienda como no presentada y, por tanto, que procedan las sanciones por no declarar o por hacerlo extemporáneamente. Esto es así por las siguientes tres razones:

- En primer lugar, es posible distinguir entre las declaraciones que no producen efecto legal alguno y las que se entienden por no presentadas. Las primeras se encuentran reguladas por el artículo 580-1 del Estatuto, mientras que las segundas lo están por el artículo 580. Frente a las declaraciones de retención en la fuente presentadas sin pago total, las cuales son de las que no producen efecto legal alguno, no existe ninguna norma que establezca que las mismas se entienden por no presentadas. Por esta razón, estas declaraciones, aunque no produzcan ningún efecto legal, se encuentran plenamente presentadas. Esto implica que con las mismas se cumple el deber de declarar y, por lo tanto, no procederían las sanciones por extemporaneidad y por no declarar.

- En segundo lugar, los efectos jurídicos de una declaración tributaria son cuatro: que se ponga en conocimiento de la administración de impuestos la ocurrencia de algún hecho relevante para la aplicación de los tributos, que se dé inició al procedimiento de gestión tributaria, que la información de la declaración sirva para determinar la actividad administrativa y de fiscalización, y que la declaración tributaria constituya título ejecutivo. Que dicha declaración se entienda como presentada no es un efecto jurídico sino algo que ocurre de facto con el hecho de presentar la declaración, a no ser que el legislador consagre lo contrario. Por esta razón, la consecuencia de la ineficacia de la declaración de retención en la fuente es que la misma no produzca ninguno de los cuatro efectos jurídicos en mención, y no que la misma se entienda como no presentada.

- En tercer lugar, de acuerdo con la jurisprudencia de la Corte Constitucional, al Derecho sancionatorio tributario se le deben aplicar los principios del Derecho penal, aunque con algunos matices. Por esta razón, el análisis para que la conducta sea conducente a una sanción se debe hacer bajo los mismos parámetros que en el Derecho pe- 
nal. Dentro de dichos parámetros encontramos el principio de la objetividad material del hecho punible, según el cual la conducta se debe ajustar exactamente a la descrita en la norma que contempla la sanción.

Las sanciones por no declarar y por extemporaneidad son las siguientes: presentar la declaración de forma extemporánea (artículo 641 del ET), presentar la declaración con posterioridad al emplazamiento (artículo 642 del ET) y omitir presentar las declaraciones tributarias (artículo 643 del ET). Cuando se presenta una declaración de retención en la fuente sin pago, así la misma sea ineficaz, se realiza una acción cuya consecuencia es que no se incurre en la conducta omisiva consistente en no presentar las declaraciones tributarias. Así mismo, si esta declaración se presenta de manera oportuna, independientemente de si la misma es ineficaz o no, no se incurriría en la conducta de presentar la declaración de forma extemporánea. Al no incurrirse en ninguna de las conductas reprochadas por las sanciones por extemporaneidad e inexactitud, no sería procedente imponerle al obligado a declarar sanción alguna. 


\section{Bibliografía}

Cahn-Speyer Wells, P. (2016). "La culpabilidad en la infracción tributaria", en Cahn-Speyer Wells. Derecho Critico: Perspectiva Tributaria. Bogotá: Legis Editores S.A.

Cermeño C.; De Bedout, J. C.; García, S. A. y Clopatofsky, C. M. (2016). Procedimiento Tributario. Bogotá: Legis Editores S.A.

Marín, M. (2015). "La estructura jurídica del tributo: el hecho generador”, en Piza, Julio Roberto. La obligación tributaria y sus fundamentos constitucionales. Primera Edición. Bogotá: Universidad Externado de Colombia.

Noreña, L. (2016). "Imposición de sanciones tributarias: La inercia jurisprudencial después de la expedición de la Ley 1607 de 2012", en Revista Instituto Colombiano de Derecho Tributario, núm. 75. Noviembre 2016. At. 143.

Piza, J. R. (2010). "Retención en la fuente y otros pagos a cuenta del Impuesto", en Piza, Julio Roberto. Curso de Derecho Tributario, procedimiento y régimen sancionatorio. Primera Edición. Bogotá: Universidad Externado de Colombia.

Piza, J. R. y Castro Arango, J. M. (2010). "Los deberes tributarios y el inicio e instrucción del Procedimiento de gestión o administración tributaria", en Piza, Julio Roberto. Curso de Derecho Tributario, procedimiento y régimen sancionatorio. Primera Edición. Bogotá: Universidad Externado de Colombia.

Rueda Mantilla, David (2016). "La declaración electrónica y el título ejecutivo dentro del proceso de cobro coactivo", en Revista de Derecho Fiscal n. 9, Bogotá: Universidad Externado de Colombia. pp. 77-91. Recibido: 8 de agosto de 2016. Aprobado: el 20 de septiembre de 2016. DOI: http:// dx.doi.org/10.18601/16926722.n9.06

Rueda Mantilla, David (2017). "Derecho penal tributario en Colombia: Reflexiones a la luz de la Ley 1819 de 2016", en Revista Instituto Colombiano de Derecho Tributario 76. Recibido: 27 de febrero de 2017. Aprobado: el 8 de mayo de 2017.

Sierra Mejía, Hernando (1999). “Obligación Tributaria”, en Derecho Tributario. Instituto Colombiano de Derecho Tributario. Segunda Edición. Bogotá: Editorial Nomos S. A.

Tamayo Lombana, Alberto (2008). Manual de Obligaciones: el acto o negocio jurídico y otras fuentes de las obligaciones. Séptima Edición, Bogotá: Ediciones Doctrina y Ley Ltda.

Velásquez, Fernando (1988). "Principios rectores del Derecho penal colombiano", en Revista Facultad de Derecho y Ciencias Políticas Universidad Potificia Bolivariana Núm. 81.

Velásquez, Fernando (2007). Manuel de Derecho penal: Parte general. Ed. Librería Jurídica Comlibros.

Zornoza Pérez, Juan José y Muñoz Martínez, Gabriel (2010). "Infracciones y sanciones tributarias", en Piza, Julio Roberto. Curso de Derecho Tributario, procedimiento y régimen sancionatorio. Primera Edición. Bogotá: Universidad Externado de Colombia.

\section{Jurisprudencia}

Corte Constitucional. Sentencia C-102 de 2015.

Corte Constitucional. Sentencia T-292 de 2006.

Corte Constitucional. Sentencia C-818 de 2005. 